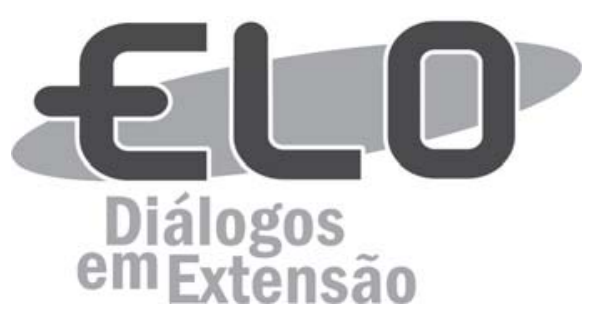

\title{
Projeto InterAção: Responsabilidade Social e Meio Ambiente
}

\author{
Ana Maria Rodrigues Costa de Castro ${ }^{1}$, Aryane Cristina Gonçalves de Souza ${ }^{2}$, \\ Daniela Grijó de Castro ${ }^{3}$, Nádia Dutra de Souza
}

\begin{abstract}
Resumo: $O$ "Projeto InterAção - Responsabilidade Social e Meio Ambiente" é um programa de extensão da Universidade Federal de Viçosa que tem como foco o fortalecimento da coleta seletiva na cidade de Viçosa (MG). Criado em 2008, o projeto tem realizado, desde então, ações de implantação e consolidação da coleta seletiva em Viçosa, buscando sensibilizar a comunidade para a mudança nos comportamentos e atitudes, além do fortalecimento das associações de catadores da cidade. Como resultado, verifica-se o aumento no número de locais que participam da coleta seletiva, bem como o aumento da sensibilização da comunidade. No entanto, falta investimento nesse setor por parte do poder público.
\end{abstract}

Palavras-chave: Coleta Seletiva. Resíduo Sólido. Responsabilidade Social.

Área Temática: Educação. Meio Ambiente. Políticas Públicas.

\section{Interaction Project: Social and Environmental Responsibility}

Abstract: The "Projeto InterAção - Responsabilidade Social e Meio Ambiente" is an extension program of the Federal University of Viçosa which focuses on strengthening the selective collection in the city Viçosa. Created in 2008, the project has made consolidation actions of selective collection in Viçosa, seeking to sensitize the community to the change in behavior and attitudes and strengthening the city's recycling associations. As a result, the increase can be seen in the number of sites participating in the selective collection, as well as increasing community awareness. However, there is a lack of investment in this sector by the government.

Keywords: Selective Collect. Solid Waste. Social Responsability.

\section{Proyecto Interacción: La Responsabilidad Social y Ambiental}

Resumen: El "Projeto InterAção - Responsabilidade Social e Meio Ambiente" es un programa de extensión de la Universidad Federal de Viçosa, que se centra en el fortalecimiento de la recogida selectiva en la ciudad de Viçosa. Creado en 2008, el proyecto realiza acciones de consolidación de la recogida selectiva en Viçosa y trata de sensibilizar a la comunidad para el cambio en el comportamiento y en las actitudes y el fortalecimiento de las asociaciones de reciclaje de la ciudad. Como resultado, el aumento se puede ver en el número de sitios que participan en la recogida selectiva, así como el aumento de la conciencia de la comunidad. Sin embargo, falta inversión en este sector por parte del gobierno.

Palabras clave: Recogida Selectiva. Residuo Sólido. Responsabilidad Social.

\footnotetext{
${ }^{1}$ Estudante de graduação em Engenharia Ambiental pela Universidade Federal de Viçosa, bolsista FUNARBEX do Projeto InterAção. Endereço: Avenida PH Rolfs, 265/304, Centro, Viçosa-MG; Telefone: (31)99464-6657; Email: anamcosta2@gmail.com.

${ }^{2}$ Estudante de graduação em Engenharia Ambiental pela Universidade Federal de Viçosa, voluntária no Projeto InterAção.

${ }^{3}$ Estudante de graduação em Licenciatura em Ciências Biológicas pela Universidade Federal de Viçosa, voluntária no Projeto InterAção.

${ }^{4}$ Professora do Departamento de Ciências Sociais da Universidade Federal de Viçosa, coordenadora do Projeto InterAção.
} 


\section{Introdução e Justificativa}

A temática sustentável tem ficado mais reconhecida a cada dia, mas ela ainda não foi capaz de provocar as mudanças necessárias no comportamento da sociedade. Nesse sentido, os resíduos sólidos se tornaram um problema sério, ao passo que sua geração está relacionada aos hábitos e costumes, difíceis de modificar no curto prazo, e sua produção têm aumentado a cada ano.

Na cidade de Viçosa (MG), as primeiras ações no sentido de solucionar a problemática da destinação dos resíduos sólidos aconteceram no ano de 2002, após o fechamento do "lixão", com a criação da Usina de Triagem e Reciclagem de Viçosa, de uma parceria da Universidade Federal de Viçosa (UFV) com a Prefeitura Municipal de Viçosa (PMV).

Verificou-se, com a criação da Usina, a oportunidade de se incluir em uma cadeia sócio produtiva pessoas socialmente vulneráveis. Os catadores que viviam no "lixão" foram desalojados e, assim, receberam a opção de trabalhar na Usina. Estima-se que cerca da metade deles aceitaram a proposta. Outras pessoas também foram trabalhar no local, todos caracterizados por baixa renda e baixa escolaridade.

Apesar de as iniciativas tomadas pelo poder público no que diz respeito ao espaço físico de destinação de resíduos sólidos, a quantidade de resíduos gerados na cidade continuou aumentando e as condições de trabalhado na Usina não eram muito diferentes das encontradas no "lixão": os materiais chegavam misturados e em péssimas condições de manipulação e venda. Era necessário um processo de sensibilização da comunidade a cerca desta temática e apoio aos catadores, que trabalhavam em condições precárias no local.

Em 2008, os trabalhadores da Usina oficializaram uma associação, a Associação dos Trabalhadores da Usina de Triagem e Reciclagem de Viçosa (ACAMARE), com o apoio da Incubadora Tecnológica de Cooperativas Populares (ITCP). Oito anos depois, esta associação trabalha no mesmo local, triando, prensando, enfardando e comercializando materiais recicláveis.

No mesmo ano de 2008, foi criado o "Projeto InterAção - Responsabilidade Social e Meio Ambiente", que veio a se tornar um programa de extensão vinculado ao Departamento de Ciências Sociais da UFV. Este projeto tem por objetivo a implantação da coleta seletiva na cidade de Viçosa e o fortalecimento socioeconômico dos catadores.

Desde então surgiram iniciativas no sentido de sensibilizar a comunidade a cerca da importância ambiental e social de sua participação na coleta seletiva, e isso vem ocorrendo a quase nove anos, envolvendo estudantes e professores de diferentes departamentos da UFV. A partir do ano de 2010, as ações do Projeto passaram a ter o respaldo de uma lei importante, a Lei $N^{\circ} 12.305 / 2010$, que instituiu a Política Nacional de Resíduos Sólidos e tem a coleta seletiva com inserção de catadores como um instrumento da gestão de resíduos sólidos.

Dessa forma, este relato de experiência tem por objetivo mostrar a atuação do Projeto InterAção na cidade de Viçosa, relatando suas ações no ano de 2016.

\section{Metodologia}

A metodologia do projeto é baseada na proposta de melhorias na coleta seletiva do município de Viçosa, buscando o envolvimento dos atores sociais: integrantes do projeto, comunidade viçosense, Serviço Autônomo de Água e Esgoto (SAAE) e catadores. Dessa maneira, a metodologia usada no ano de 2016 fundamenta-se nas seguintes ações:

\section{Diagnóstico da coleta seletiva e elaboração de estratégias}

O diagnóstico baseia-se no acompanhamento das localidades que estão sendo atendidas pela coleta seletiva no município, como edifícios, condomínios horizontais, templos religiosos, clubes, etc.

Esse acompanhamento começa por meio de contato telefônico com algum responsável pelo local (síndico, zelador ou morador). Identificado algum problema na realização da coleta seletiva na localidade, é discutido junto ao responsável algum tipo de intervenção: envio de carta ou e-mail aos moradores, afixação de placas e anúncios explicativos em locais estratégicos, exposição de fotos da Usina de Triagem e dos catadores, realização de dinâmicas em grupo, dentre outras. A atividade a ser realizada dependerá do público alvo e do interesse do responsável pelo local. 


\section{Visitas Técnicas à Usina de Triagem e Reciclagem de Viçosa e à sede da Associação dos Catadores de Viçosa (ACAT)}

O objetivo dessas visitas é verificar a quantidade e a qualidade dos materiais que chegam da coleta seletiva e o impacto no trabalho das associações. Do diálogo com os catadores é possível descobrir se o caminhão da coleta seletiva está chegando nos dias e horários combinados, qual a qualidade do material que chega, quais materiais recicláveis estão sendo comercializados, dentre outras informações.

Além disso, como o contato das associações com o poder público é dificultado, a equipe se propõe a intermediar esse contato quando necessário, contribuindo para que as demandas dos catadores sejam atendidas da melhor forma possível.

\section{Reuniões com o SAAE}

É realizada, em média, uma reunião a cada dois meses com o Diretor de Limpeza Urbana do SAAE, para repasse de demandas e reclamações/sugestões recebidas por parte da comunidade, além do planejamento de ações. Se verificada a necessidade, é convocada para essa reunião toda a equipe do caminhão da coleta seletiva, incluindo o motorista e os agentes de limpeza. Para a coleta seletiva funcionar, é fundamental considerar a percepção daqueles funcionários que lidam diariamente com esse trabalho.

\section{Divulgação da coleta seletiva e sua importância social, ambiental e econômica}

Compreendem-se as redes sociais e os sites como meios de atingir um número maior de pessoas de forma mais rápida e eficiente. Portanto, a coleta seletiva em Viçosa também é divulgada por meio de ambientes virtuais como o Facebook e o site do Projeto InterAção. São publicados e atualizados com frequência os locais, dias e horários da coleta, bem como o modo de participar da coleta seletiva. As redes sociais são entendidas como um mecanismo de educação ambiental, então todos os temas pertinentes também são veiculados.

\section{Ações realizadas em 2016}

- Participação em uma reunião para implantação da coleta seletiva no bairro Inácio Martins, juntamente ao SAAE, líderes religiosos da região e moradores do bairro, com o propósito de definir os dias e horários da coleta seletiva no bairro, além de definir os agentes multiplicadores para a sensibilização sobre a implantação da coleta seletiva no local;

- Realização do evento "Coleta Seletiva em foco", com o intuito de buscar possíveis parceiros e sugestões para balizar novas ações. $\mathrm{O}$ evento contou com a participação da equipe do Projeto InterAção, ITCP, Lorene Castro da Costa Rodrigues (Psicóloga do CRAS Viçosa), Ulisses Bifano Comini (Divisão de Gerenciamento de Resíduos da UFV);

- Participação no evento "Tecnologias Sociais Aplicadas a Viçosa e Região", promovido pela Agência de Desenvolvimento de Viçosa e Região (ADEVI), proferindo palestra;

- Organização de oficinas "Teatro do Oprimido", realizadas na ACAMARE, juntamente à professora Emiliana Maria Diniz Marques, do Departamento de Educação, e ITCP;

- Realização de entrevista para o Programa Contrarregra, da TV Viçosa, UFV, sobre o tema "coleta seletiva em Viçosa";

- Oficina com o Grupo de Escoteiros Viçosa, envolvendo crianças e adolescentes entre 11 e 14 anos na temática "Resíduos Sólidos" e visita à Usina de Triagem;

- Reunião com as Administradoras de Condomínios em Viçosa, para identificar os responsáveis pelas localidades atendidas pela coleta seletiva;

- Divulgação constante sobre a coleta seletiva em redes sociais como o Facebook (www.facebook.com/ projetointeracaodcs) e o site do Projeto (www.projetointeracao.ufv.br), além de jornais e rádio;

- Doação de botas, luvas e ferramentas para a ACAMARE;

- Realização de reuniões com SAAE e ITCP, para repasse de demandas e planejamento de novas ações; 
- Exposição "Árvore das Virtudes" (Figura 1) construída com materiais recicláveis provenientes da Usina de Triagem, por intermédio de uma oficina oferecida no $2^{\circ}$ semestre de 2015 para os catadores da ACAMARE, nos locais: Museu Pinacoteca, Departamento de Ciências Sociais, Departamento de Letras e Departamento de Ciências Biológicas;

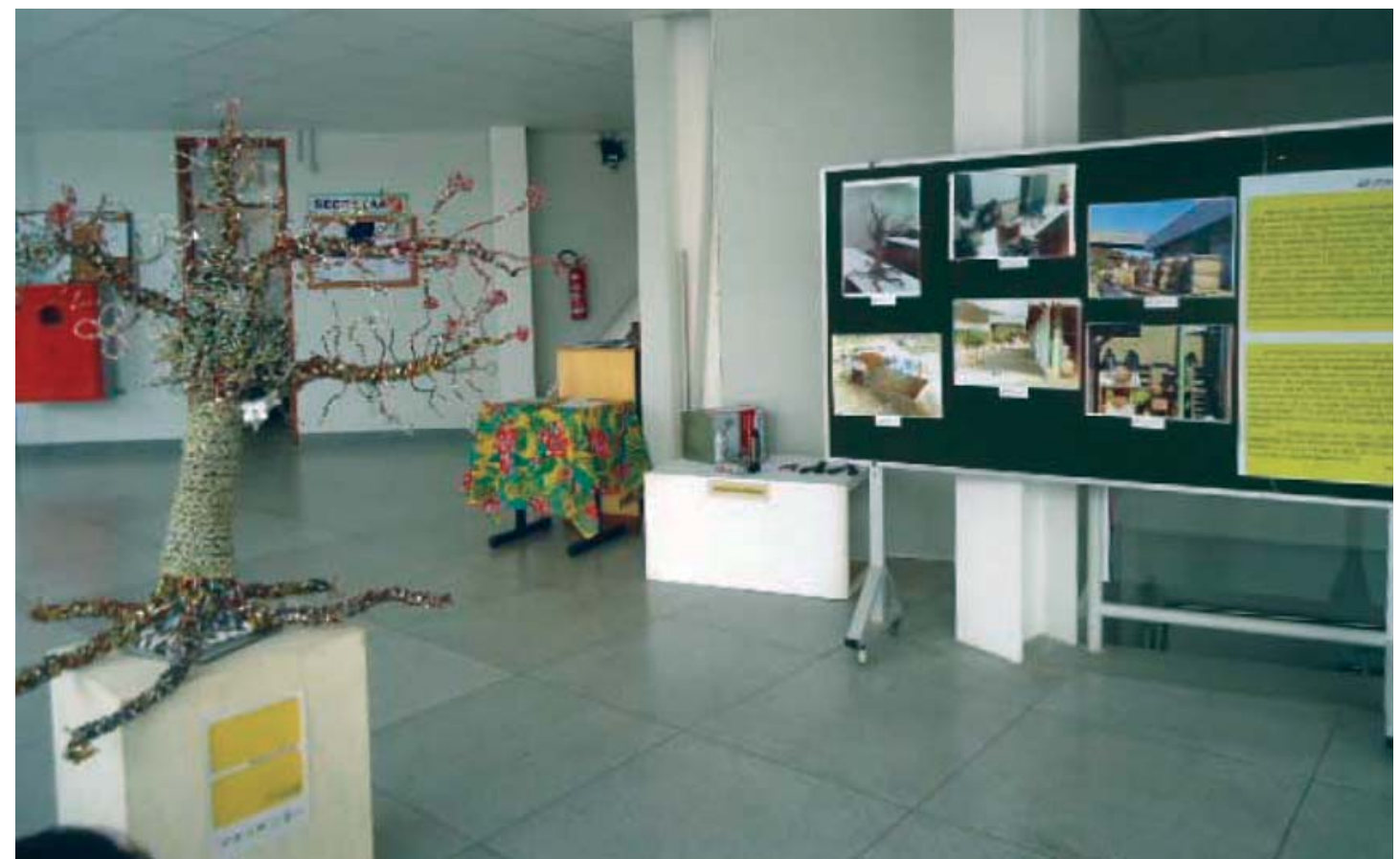

Figura 1 - Foto da Exposição "Árvore das Virtudes" no Departamento de Ciências Sociais da UFV, em agosto de 2016.

Fonte: Banco de dados do Projeto InterAção, 2016.

- Realização de visitas à Usina de Triagem (Figura 2) e à sede da ACAT;

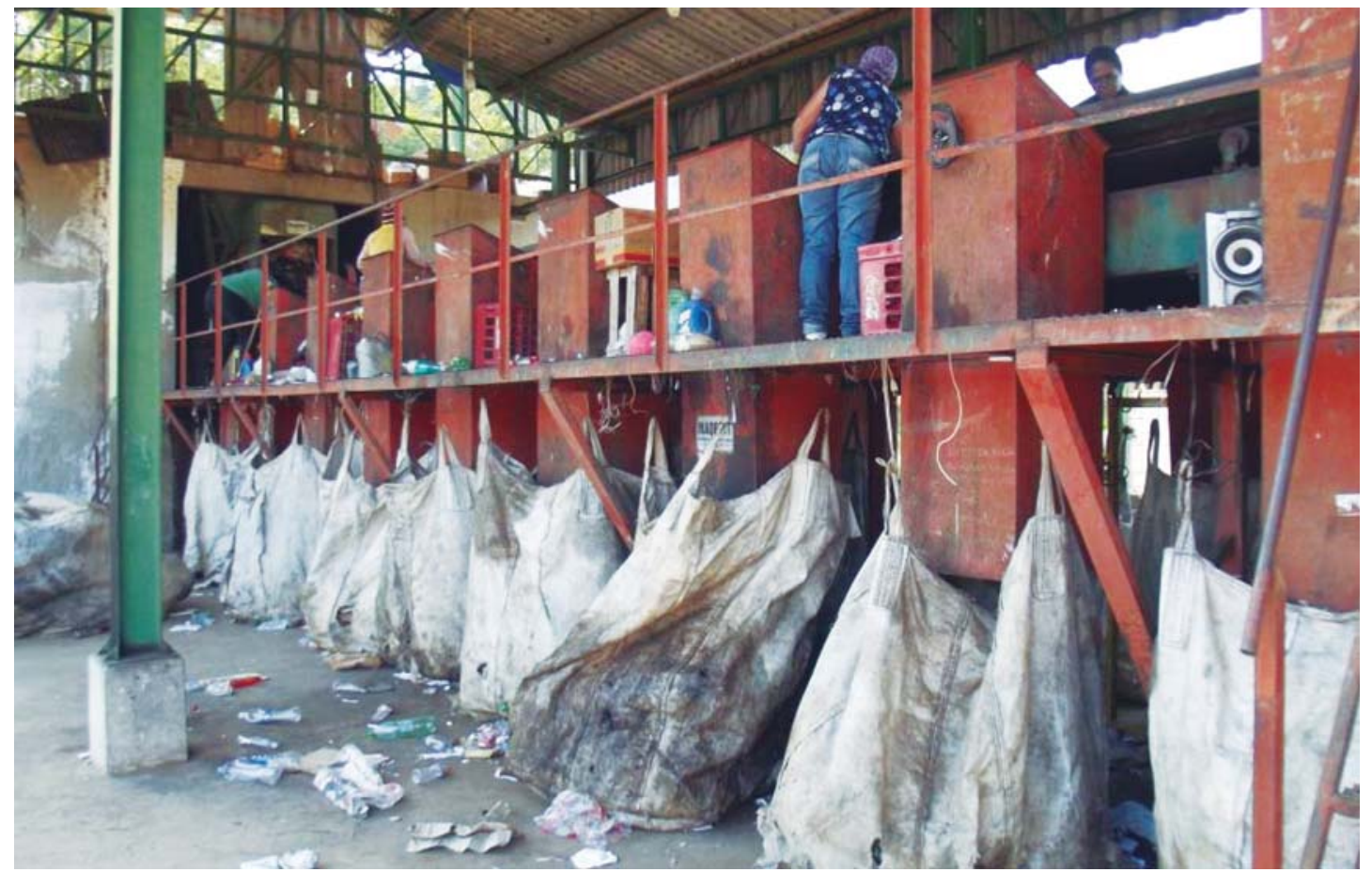

Figura 2 - Foto da esteira de triagem da Usina de Triagem e Reciclagem de Viçosa.

Fonte: Banco de dados do Projeto InterAção, 2016. 
- Palestra no evento "Capacitação sobre Plano Municipal de Gestão Integrada de Resíduos Sólidos", realizado pelo Grupo de Extensão e Pesquisa em Saneamento Ambiental do Departamento de Engenharia Civil;

- Participação de plenária com catadores da Zona da Mata mineira, na Troca de Saberes 2016, da Semana do Fazendeiro (Figura 3);

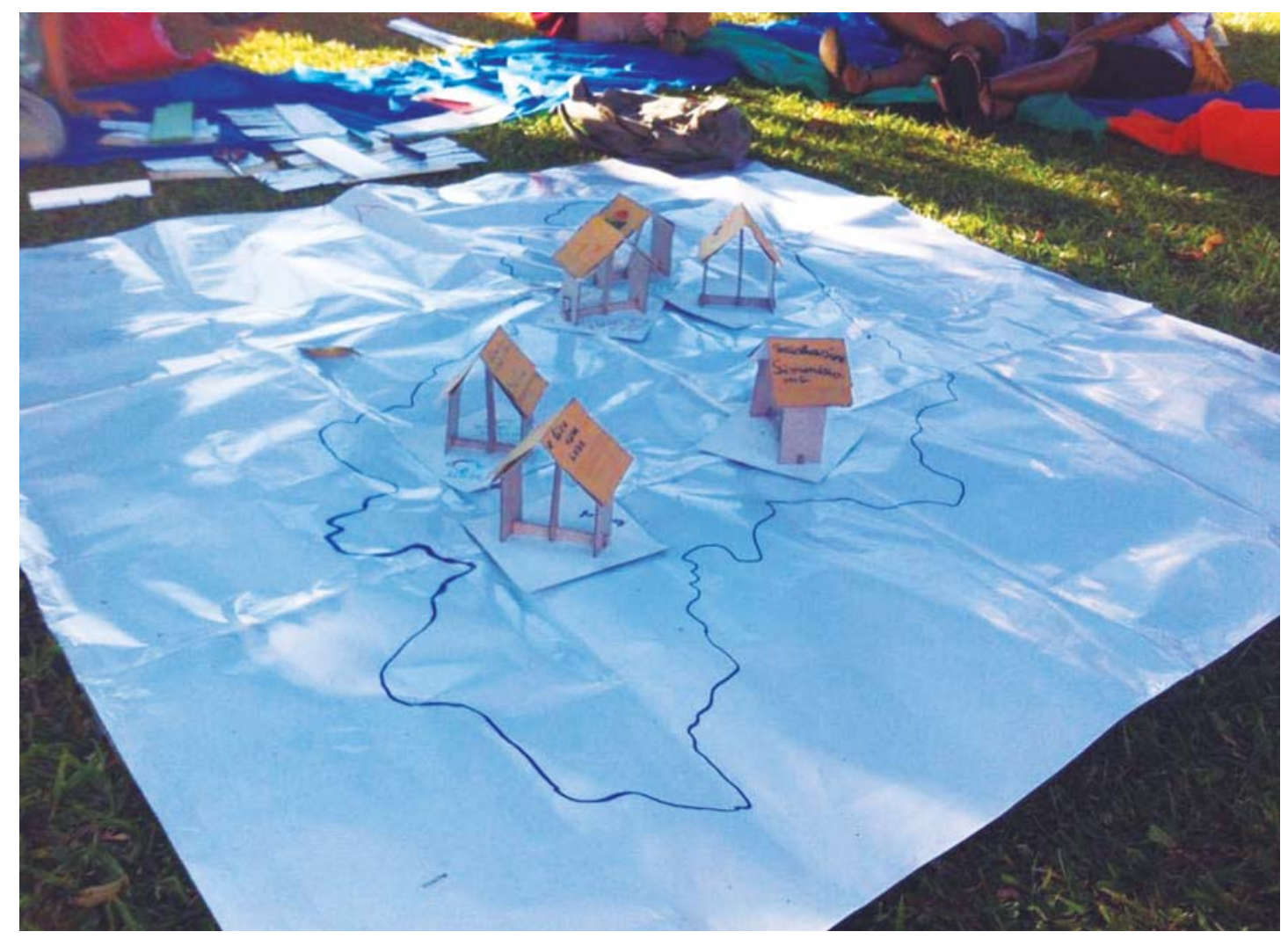

Figura 3 - Foto da dinâmica realizada durante a plenária, em que cada casa representa uma das instituições presentes (associações de catadores e projetos da UFV).

Fonte: Banco de dados do Projeto InterAção, 2016.

- Sensibilização dos moradores do edifício Porto Belo (Rua Vaz de Melo);

- Realização de reunião com o promotor Bruno Muller, em busca de orientações que guiem os trabalhos do projeto;

- Reunião com representante da Coordenadoria de Inclusão e Mobilização Sociais (CIMOS) do Ministério Público de Minas Gerais, que veio a Viçosa por solicitação do promotor Bruno Muller verificar a situação dos catadores da cidade;

- Estudo de campo na Escola Estadual Santa Rita para reimplantação da coleta seletiva no local, incluindo reunião com diretora e vice-diretora, conversa com funcionários da limpeza e verificação das condições físicas do local;

- Reunião com moradores do bairro Belvedere para auxiliar na sensibilização da comunidade residente no local para realização da coleta seletiva, identificada com problemas;

- Intervenção porta a porta com estabelecimentos comerciais do bairro Belvedere para divulgação da coleta seletiva;

- Palestra para capacitação de funcionários das escolas Santa Rita, Passo a Passo e Laboratório de Desenvolvimento Estudantil da UFV sobre a coleta seletiva;

- Participação no evento IX Simpósio de Meio Ambiente organizado pelo Centro Brasileiro para Conservação da Natureza e Desenvolvimento Sustentável, com publicação dos trabalhos: "Coleta Seletiva em Viçosa: uma demanda da comunidade", "Coleta Seletiva na Escola Estadual Santa Rita de Cássia: formando multiplicadores" e "Construção da Coleta Seletiva em Viçosa-MG"; 
- Participação no evento ExpoCatadores 2016, apresentando o trabalho “A contribuição do Projeto InterAção para o trabalho dos catadores em Viçosa-MG";

- Apresentação de trabalhos no Simpósio de Integração Acadêmica da UFV: "Construção da Coleta Seletiva em Viçosa-MG: Novos Rumos" e "Estágio da Engenharia Ambiental no Projeto InterAção".

\section{Conclusão}

O Projeto InterAção atua despertando os moradores da cidade de Viçosa para sua responsabilidade social, por meio da capacitação dos agentes sociais para que eles mudem a realidade onde estão inseridos, exercendo sua cidadania. Assim, busca-se efetivar uma política pública, que é a Lei $\mathrm{N}^{\mathrm{o}} 12305 / 2010$.

Durante os quase nove anos de atuação do Projeto InterAção em Viçosa, verificou-se o aumento no número de locais que participam da coleta seletiva, bem como o aumento da sensibilização da comunidade para esta temática. No entanto, atualmente está evidente a precariedade da coleta seletiva na cidade, que pode ser atribuída à falta de iniciativas nesse setor por parte do poder público.

Percebe-se que falta a criação de leis em Viçosa e a aplicação real de políticas públicas. O apoio e a efetiva parceria por parte do poder público, solucionando problemas, ouvindo sugestões e efetuando mudanças, é fundamental para a concretização dos objetivos deste Projeto.

\section{Fontes de Financiamento}

O Projeto InterAção está executando no ano de 2016 o projeto “Construção da Coleta Seletiva em Viçosa (MG): Novos Rumos", com bolsa do Programa da Fundação Arthur Bernardes de Apoio à Extensão (FUNARBEX).

\section{Agradecimentos}

Faz-se um agradecimento especial a todos que já contribuíram com a trajetória do Projeto InterAção: estudantes e professores que já fizeram parte desta equipe, catadores da ACAMARE e ACAT, bem como as equipes do ITCP e SAAE.

\section{Referências Bibliográficas}

BRASIL. Lei $N^{o}$ 12.305, de 02 de agosto de 2010. Institui a Política Nacional de Resíduos Sólidos; altera a Lei $\mathrm{n}^{\circ}$ 9605, de 12 de fevereiro de 1998; e dá outras providências. Disponível em: <http:// www.planalto.gov.br/ccivil_03/_ato2007-2010/2010/lei/112305.htm>. Acesso em: 14 dez. 2016.

Recebido para publicação em 23/10/2016 e aprovado em 20/12/2016. 